\title{
The Reproductive Advantages of Fat in Women
}

\author{
T. M. Caro and D. W. Sellen* \\ Evolution and Human Behavior Program, University of Michigan and \\ *Department of Anthropology, University of Michigan
}

\begin{abstract}
Many hypotheses have been proposed for the evolution of fat deposition in women. Here we examine the empirical basis of the deceptive fat hypothesis. The available evidence suggests that body fat has direct effects on reproduction in women regardless of whether or not it is a signal of condition.
\end{abstract}

KEY WORDS: Women; Sexual selection; Deception; Fat deposition; Breast; Pelvis.

\section{INTRODUCTION}

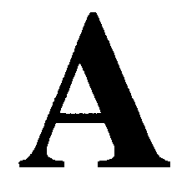

number of proposals have been advanced to explain the evolutionary significance of sex-specific fat distribution in women, focusing primarily on the premature development of breasts in nulliparous human females and consequent permanent breast enlargement (e.g., Cant 1981; reviewed in Caro 1987). Recently, Low et al. (1987; henceforth referred to as LAN) (see also Low et al. 1988) proposed the hypothesis that the sex-specific distribution of fat on women's breasts and on hips deceives men as to their bearer's reproductive status (see also Alexander 1971; Low 1979). Their argument is properly based on the individual as the unit of selection. They work from the assumption that "breasts, hips and buttocks evolved in the context of females competing for the attention and parental commitment of powerful resource-controlling males." Then, arguing that fat laid down in the pelvic and breast areas is ambiguous because it could be confused with a wide pelvis or with glandular tissue, respectively, they reason that fat storage in such areas, respectively, deceives men of the "ease" with which parturition occurs and the ability to produce and store milk. In contrast, they believe that steatopygia (fat dcposits on the buttocks) is an unambiguous and, therefore, honest display of fat reserves because it cannot be confused with other tissue. Through de-

Received April 13, 1988; revised March 21, 1989.

Address reprint requests to: Dr. Tim Caro, Evolution and Human Behavior Program, Rackham Building, University of Michigan, Ann Arbor, MI 48109-1070. 
ception, it is argued, certain females (with intrinsically lower reproductive potentials relative to nondeceivers) attempt to enhance their reproductive output by attracting either "high quality" males or males particularly willing to invest in raising offspring.

In this article, we argue that there are theoretical reasons for questioning whether deception in particular, and sexual selection in general, can have been an important evolutionary force in shaping and maintaining the distribution of fat in women. Then we examine the validity of a number of assumptions of the deceptive fat hypothesis. In the last section, we briefly review the evidence that accumulation of body fat on women has direct effects on fertility independent of effects on mate choice.

Before proceeding, we take as given that there is a human female pattern of fat distribution different from that of human males and that from other female primates, although no satisfactory functional explanation for these differences has yet emerged. With specific reference to breasts, we will not be concerned with the arguments over the signal value of the presence versus the absence of breasts, but with the signal value of variations between individuals in breast morphology. Last, as in the study of nonhuman animals, discussion of mate preferences does not imply conscious decision making by males.

\section{THEORETICAL WEAKNESSES OF THE DECEPTION HYPOTHESIS}

\section{A Point of Clarification}

There are two possible interpretations of the "Deception Hypothesis." In the first interpretation, breast size is thought to predict lactational output, and latero-pelvic width to predict the size of the birth canal (and, hence, the "ease" of parturition) for the majority of women. Under such starting conditions, a minority of women, who sequester fat in these regions of the body, could thereby mimic these signals of reproductive capability without actually being able to provide the same milk supply or give birth as successfully. In the second interpretation, breast size is thought honestly to have predicted lactational potential, and hip width ease of parturition in the past, but no longer in contemporary populations. These two possibilities are central to LAN's arguments, but it is helpful to separate them in order to devise appropriate tests of the hypothesis. If, for example, it was found that breast size is a predictor of lactational output in some women but not in others, then this would clearly distinguish their first possibility from the second, which predicts no relationship between breast size and lactation in any contemporary women.

Irrespective of which scenario is proposed, morphological features that function as dishonest signals (Trivers 1985) are not likely to be evolutionarily 
stable because selection will eventually favor receivers of the signal (here, conspecific males) who come to recognize that the signal conveys dishonest information (see Krebs and Davies 1987). Increasing numbers of cheaters in a contemporary population would severely reduce the associations between body characteristics and both lactational output and ease of birth. Hence, the strength of selective pressures on males to choose these largebreasted women or women with wide hips would soon diminish.

In proposing that female fat distribution deceives males of females' "reproductive probability," L.AN implicitly assume that it is extremely difficult to men to detect "cheating" females and that, for women, the costs of cheating are relatively low compared to its benefits. These assumptions are now examined in the light of the available facts.

\section{Detecting Cheating Females}

Physicians can assess the degree to which hips are composed of fat by tactile means. There is no reason to think that there has been insufficient evolutionary time for men to evolve ways to make such assessments. Nor are such judgments a costly activity in view of the amount of touching and squeezing that occurs during courtship and prior to copulation in those societies sampled (Broude and Green 1976; Frayser 1985).

Consider however, that there has indeed been insufficient time for males to be able to judge the composition of breasts by tactile means. Then it would pay even truly well-endowed women (with abundant breast glandular tissue) to deceive men by laying down increasing amounts of fat in this area. If we assume that there is some cost to having too much fat (e.g., Seidell et al. 1985), and males chose mates on the same criterion, we might expect to see females converge on some optimum shape. The observed wide variation between individuals in fatness, weight, and shape implies that this has not occurred. In fact, rates of change of fatfold thicknesses per unit gain (or loss) of weight remain similar over a wide range of body weights and total body fatnesses at several sites, suggesting that there is no approach to an optimum fatfold value in any body region (Garn et al. 1987).

Alternatively, if we assume there is no cost to being fatter than competitors but only a benefit of attracting "high quality males," we might expect the vast majority (perhaps all) women disproportionately to sequester fat in breasts (and on hips) so as to enhance their true dimensions in these regions whenever they can. We know of no evidence that suggests that this happens when an individual woman gets fatter. The only relevant data published shows that 1) lower trunk sites (abdominal and iliac) have higher rates of change than upper body sites (triceps, subscapular) and that 2) there is no sex difference in this pattern of slightly preferential deposition at lower trunk sites (Garn et al. 1987). Certainly, we can conclude that when women put on fat, it is not only deposited on breasts and hips. We need to analyze 
the anthropometric data to determine whether the fat is preferentially deposited on breasts and hips as opposed to the other female-favored areas.

In sum, the fact that women do not simply deposit fat on their breasts and hips as opposed to other female-favored areas, such as buttocks and thighs, is strong evidence against breasts and hips acting as signals of deception. Nevertheless, the theoretical possibility that breasts signal their bearer's reproductive potential after they cross some size threshold and that further fat is deposited elsewhere in the body cannot be dismissed.

\section{Costs of Cheating}

If the costs to a female of having fat in breasts and on hips are minor compared to having less or no fat in these regions, then it follows that selective forces acting on males to be able to discern breast and hip composition will have been weak. This is because their potential mates will be little affected by the extra fat deposits they carry. As the ratio of costs to benefits diminishes, the role of deception (and the Deception Hypothesis) is reduced, and the importance of honesty increases. To our knowledge, it has not been shown that large breasts impose costs on their bearers. The observation that large-breasted women are under-represented among top athletes in most track and field events, although supportative, may be an artifact of differences in hormonal physiology associated with low total body fat (Graham 1985; Malina 1983). The only data available that suggest a cost associated with fatness are concerned with the various pathological conditions associated with clinical obesity (e.g., Keen et al. 1982; Larsson et al. 1984; Seidell et al. 1985) which are probably of minor import in most populations and so are not relevant to this discussion. However, even these morbid conditions are associated with male (upper body) patterns of fat deposition rather than the characteristic female (lower body) patterns. With no evidence to show that breast and hip fat is costly, it is difficult to perceive that the benefits will have favored deception.

\section{ASSUMPTIONS OF THE DECEPTION HYPOTHESIS}

The Deception Hypotheses aims to combine several interesting models from evolutionary theory in an attempt to produce a complex hypothesis. The attempt necessarily involved making many assumptions. Here, we make some of these assumptions explicit and examine the empirical evidence for them.

\section{Evidence that Males Universally Invest Heavily in Offspring}

Two important assumptions of the Deception Hypothesis are that a man invests considerable resources in raising his wife's children (his own), caus- 
ing him to exercise care in choosing his spouse, and that men who invest in their offspring have higher reproductive success than those who do not. (We take LAN's opening clause "when males invest parentally" to mean more than just providing sperm. Their argument can only apply to those contexts where a male will subsequently invest in offspring and not to those many situations where investment only takes the form of copulations.)

There is no strong evidence to show whether males did or did not invest in their offspring in the period of humankind's evolution when breasts and fat on hips were thought to have appeared. Among extant hunter gatherers, an arguable analog for these extinct societies, there is little property, either real or moveable, that can be transferred to offspring (Gray and Wolfe 1981). Regarding other forms of investment among hunter gatherers, Ache men, for example, do not preferentially fced their own wives or children in comparison to other members of the group (Kaplan and Hill 1985), although they may protect their offspring from other males (Hill and Kaplan 1988). Similarly, among the Ye'kwana, male parental investment in offspring is low, and time and effort is preferentially spent on increasing mating opportunities (Hames 1988). Among other extant societies in which resources are inherited, there is great variability in the degree to which men invest in their own offspring. The important point to note is that considerable male investment in offspring in these and other societies cannot be taken as the rule, and the question of the extent of male parental investment in prehistoric human societies must remain open. Finally, although humans are characterized as a species where male parental investment is high (Strassman 1981), we know of no studies where quantitative data unequivocally show that male investment in offspring increases their reproductive success.

\section{Locomotory Costs of Wide Pelvises}

LAN state that "extremely wide pelvises might interfere with locomotion deleteriously, especially before the establishment of a pair bond." From an analysis of the mechanics of pelvic dimorphism, La Velle Moerman (1981) suggested that sex differences in pelvic anatomy were not sufficient to produce differences in the mechanics of locomotion. Observational evidence also indicates that contemporary women do not have locomotively inefficient pelvises. Women in almost all traditional subsistence societies show high work output (Ember 1983). In hunter-gatherer groups, women walk considerable distances to achieve high foraging returns (Estioko-Griffin and Griffin 1981; Lee 1968). In cases where sexual division of labor exists in such groups, it is due to women with children undertaking the less risky activities, not those that are less physically demanding (Hurtado et al. 1985). The high work load undertaken by women in nearly all societies suggests that women are not impeded by their pelvic anatomy, questioning whether males might have gained by favoring wider pelvises than were advantageous to women in the past. 


\section{Evidence that Fat Deposits are Signals to Males}

A third assumption is that breasts, hips, and buttocks serve as sexual signals to males. In support of breasts acting as signals, there is evidence from several sources to show that some men in certain subsets of Western societies find breasts attractive (e.g., Wiggins et al. 1968). However, the extent to which males in other societies find breasts and hips attractive is not known, and cross-cultural data on men's preferred female body builds have not yet been collected.

In fact, breasts are tremendously variable between individuals on a range of measures (Boston Women's Health Book Collective 1984). For the same individual, premenstrual changes in breast volume are marked in nonpregnant women (Johnston and Everitt 1984), which suggests that any choice involving fine discrimination based on breast volume may be less reliable than structures not influenced by hormonal cycling. A separate point concerning the signal function of breasts is LAN's suggestion that males will prefer "moderate to pale pigmentation of the nipples (e.g., breasts typical of nonpregnant young women)." There are no data to support this as yet, and it may not be applicable across societies because the importance of nipple pigmentation diminishes in very dark-skinned populations.

Perhaps the most important issue here is that the Deception Hypothesis ignores the possibilities of choice for other criteria. Among the Kipsigis of Kenya, men pay higher bride-prices for generally plump women (Borgerhoff Mulder 1988). Among the Kel Tamasheq nobles of Mali, men find fat and the number of fatfolds on the upper arms highly attractive (D. Sieff, personal communication); upper-arm fat is the most unambiguous predictor of total body fat in women (Garn 1979). Skin texture, muscle tone, lively demeanor, and an assessment of a woman's mother's and sisters' reproductive success (all of which could correlate with fitness) might easily be used by males in choosing their mates. Given these and other possibilities, there is a need for systematic studies of the culturally specific criteria on which men choose mates. Furthermore, such studies must discriminate between the factors that men use in the choosing of wives, and in the choosing of mates, which may not always concur. Until such studies are performed, it is premature to suggest that breasts, hips, and buttocks are particularly salient criteria of choice in view of the many other criteria on which mate choice is made (Buss 1989).

\section{Evidence that Female Fat Deposits Deceive Males}

The Deception Hypothesis hinges on the assumption that fat laid down in breasts or on hips is not advantageous to the bearer independent of its putative effects through mate choice. As yet, there is no evidence in support of this. It is equally reasonable to argue that men may be choosing for fat per se, that fat on the hips is easy to see because it forms the body's outline 
when viewed from the front or behind, and that fat deposited on the breasts of a normally flat-chested individual will provide an unambiguous display of fat stored over the rib cage. To provide empirical evidence for the Deception Hypothesis, it needs to be shown that men cannot discriminate between females who have wide pelvises and those who have fatty hips. Moreover, it needs to be demonstrated that in contrast to breast and hip fat, fat stored in other regions (on the buttocks, inner thighs, shoulders, and upper arms) does not deceive males of their bearer's reproductive potential.

\section{Evidence that Breast Volume Predicts Lactational Output}

One interpretation of the Deception Hypothesis requires that breast size correlates with the ability to store and produce milk in some women but not in others. It is surprising that there is so little information on the relationship between breast size and lactational ability. However, the limited data show that breast volume is not associated with milk production. In nulliparous women, glandular development is an arrested state but during early pregnancy, the entire ductular-lobular-alveolar system undergoes considerable hypertrophy (Johnston and Everitt 1984). Although increases in breast volume during pregnancy do correlate with subsequent lactational performance (Hytten 1954), no studies have been carried out to determine whether this recruitment of glandular tissue during the first trimester of pregnancy is proportional to prepregnancy breast size. In all probability, nulliparous breast size bears little relationship to lactational performance (Hytten and Leitch 1971).

During the third month of pregnancy, breast volume of primiparous mothers did not correlate positively with milk produced on day 7 postpartum, but the number of individuals measured was admittedly small $\left(N=9, r_{s}-\right.$ 0.24, NS, calculated from Hytten 1954).

After parturition, the rate of secretion of milk by the alveolar cells of the breast is under the control of prolactin released during feeding as a result of nipple stimulation (McNeilly 1977). The frequency and strength of suckling by the infant in part determines subsequent rate of secretion (Prentice et al. 1983), as does maternal nutritional intake (Louden et al. 1983), so that even postpartum alveolar size may not be a very good predictor of lactational output. Indeed, empty breast volume on day 7 postpartum was only significantly positively correlated with milk output on the same day in primiparous mothers $\left(N=86, r_{s}=0.31, p<0.01\right)$ but not in multiparous mothers $(N$ $=23, r_{s}=0.35$, NS); nor was there any relationship between breast volume on day 7 and milk quality on day 7 (Hytten 1954). It is true that these results are difficult to interpret because sample sizes were small and milk yield on day 7 may be a poor indicator of overall milk yield and quality during the course of lactation. However, relatively invariant milk output in the face of nutritional stress (Delgado et al. 1982), compensatory milk output in women with unilateral breast dysfunction (Prentice et al. 1986) and adjustments of 
lactational output to the death of a twin, size of the infant, and its rate of growth (e.g., Bowen-Jones, et al. 1983) all suggest that the association between breast volume and milk output really is weak.

Although limited, the empirical data suggest that the version of the Deception Hypothesis that demands breast size predicts lactational potential in the majority of contemporary women is not supported. In view of this, only if all women in Western societies are deceiving men of their "reproductive probability" could the Deception Hypothesis work, yet considerations outlined in the previous sections suggest that it is unlikely this can occur.

\section{Data Show Pelvic Width and Iliac Canal Width Are Not Linked to Obstetric Complications}

The Deception Hypothesis requires that "hip width" either correlated with ease of giving birth in the past (which we take to mean the probability of cephalopelvic disproportion [CPD] preventing parturition) or does so nowadays in the majority of women. It is not explicit as to which of several possible measures of pelvic diameter the model refers. In fact, there are three questions that must be teased apart: 1) whether the architecture of the birth canal or "true pelvis" (internal pelvis below the plane of the inlet) is associated with ease of parturition; 2) whether any of the various dimensions of the external pelvis have any statistical assuciation with the dimensions of the birth canal; and 3) which of these external dimensions of the pelvis have thick fat deposits over them, which increase the apparent dimensions to an observer. We consider these in turn.

1. CPD undoubtedly causes complications during birthing, irrespective of the presentation of the fetus, with problems arising at the pelvic inlet, the midpelvis, or the pelvic outlet (Llewellyn-Jones 1982). CPD can result from a great number of factors, reducible to any factors that produce a largeheaded infant or an unusual shape to any part of the birth canal. However, the latter is more complex than simply "size" of the birth canal. For example, using the Caldwell-Moloy classification of pelvic shapes, in women with "android" pelvises (small anterior-posterior diameter, especially at the outlet), there may be difficulty when the baby's head is rotated into the vertical plane (occiput posterior presentation) during the rotation phase of labor, while in women with "platypoid" pelvises (small lateral diameters), there may be arrest in the extension phase of labor (Oxorn 1986). Although the pelvic midplane and outlet exert the most critical effects on birth outcome with respect to CPD (Greene and Sibley 1986), shoulder-pelvic disproportion can be the most important factor if the pelvic inlet is small in the transverse plane relative to fetal shoulder girth. Trevathan (1988) notes the possible importance of this in the evolution of the human reproductive system. It is important to specify to which zones of the birth canal the model refers.

In fact, width of the birth canal does not predict complications during 
parturition. Studies of antenatal radiograms have shown that pelvic size is not correlated with the incidence of difficult outcomes of labor (e.g., Russell and Richards 1971), because there are so many other causes of birth complications. Furthermore, actual CPD cannot be predicted even when a radiograph taken at the start of labor shows the fetal cranial size to be greater than the maternal inlet diameter (Russell 1973). Successful birthing is quite likely because during parturition a) the pelvic ligaments relax under the influence of progesterone and relaxin (Borell and Fernstrom 1957; Stewart 1984), and b) and the fetal cranium is moulded greatly because its sutures are not fused allowing the bones to overlap by between $5-10 \mathrm{~mm}$ (Kriewall and McPherson 1981).

In addition, there is good evidence that size of the neonate is strongly determined by maternal physiology: Smaller women (with smaller iliac canals) give birth to smaller neonates mediated through reduced placental weights (Frisancho et al. 1977; Naeye 1981) and are unaffected by paternal size (S. Garn, unpublished data.). This immediately reduces the cost to a male of mating with a woman with small pelvic dimensions.

Finally, within a population, CPD affects short women more frequently than tall women (Kennedy and Greenwald 1981), because of the greater influence on infant size of maternal weight than of maternal stature (see Rosenburg 1988 for a discussion). If there really was an advantage for males to choose mates with a low risk of suffering CPD in particular, height appears to be the best predictor measured so far. Moreover, the incidence of CPD varies between populations, independently of nutritional and socioeconomic effects (Llewellyn-Jones 1982), and it must have some genetic basis. European populations are more susceptible than some Asian and African ones. According to the Deception Hypothesis, we might expect Europeans with small pelvises to deposit more "deceptive" fat on hips than small-hipped women from other populations, but we know of no evidence for this.

There is one further caveat to add here. In modern humans, physical "ease of parturition" may not be the most important factor affecting the success of parturition. Trevathan (1987) discusses the important effect of assistants at every stage of human labor, which differs from the typical primate pattern of labor in ways that make it more difficult for a human mother to complete it successfully on her own. There has been evolutionary change in the orientation of the fetus and, hence, its entire emergence pattern contingent upon the evolution of the more "gynecoid" female pelvis associated with bipedalism and encephalization. The care of the "extero-gestate" human fetus also involves a complex social support network for the mother. If these factors really are as important in hominid reproductive success as some would argue, the influence of physical attributes of a woman are reduced, and the relative benefits to human males choosing such are diminished.

2. Regarding the second question, it is clear from this discussion that the dimensions of the "false pelvis" must have little effect on the ease of 
parturition, even if correlations with internal dimensions are strong. Many obstetrical texts mention some degree of correlation between internal and external pelvic dimensions; many also note that the outer dimensions have little obstetrical importance. However, the evidence for the former has been based largely on very small samples from rather atypical skeletal populations of women; more data are needed to establish correlations applicable to the general human population. What seems relevant here is that within any population, there is great variation in inlet pelvic shape at any given pelvic size (giving rise to terms such as gynecoid, etc.)

Certainly, in the earlier years of a woman's reproductive life span, correlations between internal and external pelvic dimensions are weak and dependent on many factors. A longitudinal radiographic study of well-nourished young women showed the inlet and outlet of the birth canal were significantly smaller at menarche, when about 90 percent of adult size has been achieved for several iliac widths, than at age 18 (LaVelle Moerman 1981). Much growth, excavation, and molding occurs in the pelvic basin through late adolescence, which is not externally detectable (LaVelle Moerman 1982). Thus, the association between iliac width and size of birth canal changes with age. Moreover, transverse iliac widths and circumferences of the iliac canal are contingent upon complex growth patterns of the joint cartilages, maturational timing, and response to changing hormone levels, all of which vary greatly between individuals, and correlations between them are therefore weak or nonsignificant at all ages of adolescence (LaVelle Moerman 1982).

3. The last question, regarding the location of female fat pads, is unanswerable at present because of a lack of data. We can find no clear study or discussion of the fat deposits at various locations over the human female pelvis, and it seems they have never been measured for any population. Most studies employ measures of fat folds above or behind the iliac crests, or on the upper legs (e.g., Sjostrom et al. 1972), but not of fat folds directly over the iliac crests (which sometimes constitute the most widely separated points of the pelvis in men and some women), over the articulation of the femur and pelvis, (which is usually the widest dimension of the bony pelvis in women), or over the posterior pelvic insertion of the gluteus maximus (the area most women concerned about their weight or body imagery describe as the fattest part of their body). This lack of data makes it difficult to draw conclusions about exactly which pelvic dimensions are most accentuated by fat deposits in women of any given body shape at any given fatness level. If the variability is as great as it appears, it will obscure clear relationships and, thus, reduce the possibility of dishonest signaling to potential male mates.

\section{EVIDENCE THAT BODY FAT HAS DIRECT EFFECTS ON REPRODUCTION IN WOMEN}

In a variety of mammal species where the effect has been studied, the mother's body weight is correlated with offspring survival and age at onset of 
reproduction, probably because hcavier mothers give birth to heavicr offspring (e.g., Saether 1985). In women, the available data suggest that access to resources (reviewed by Borgerhoff Mulder 1987), socioeconomic status (Garn et al. 1977; 1978; Nabarro 1981) and body fat (Bongaarts 1980) are related to a number of components of reproductive success, including offspring survival and age at menarche. Therefore, at this stage it is more parsimonious to consider that fat is of direct advantage to the individual fitness of the female, independent of its effects through mate choice.

In humans, the most important determinant of neonate size is weight gain during pregnancy (Garn and Pesick 1982), and this strongly correlates with an increase in percent of body fat (Keys et al. 1972). These factors, in turn, depend on maternal prepregnancy weight and body fat (Frisancho et al. 1971; Garn and Petzold 1983) as well as nutrition and fat-dependent cnergetic expenditure during gestation, i.e., after selection by the male (Prentice and Whitehead 1987; Prentice et al. 1987). Heavier and fatter babies remain the taller, fatter, and heavier individuals in their cohorts through much of childhood and grow faster (Garn 1985; Garn and Keating 1980; Garn and LaVelle 1985a; Garn et al. 1983).

Clearly, maternal size and fatness have a powerful effect on the size and fatness of children long after birth. Recent longitudinal studies in populations under nutritional stress show that children who are thin by anthropometric criteria have an increased likelihood of death (Chen et al. 1980). Low maternal prepregnancy weight is also a major risk factor for fetal abnormality, prematurity, low birthweight and death as outcomes of pregnancy (reviewed by Garn and LaVelle 1985b), in that it is associated with low fetal hemoglobin concentrations and long interbirth intervals (but see Garn and Petzold 1982).

These positive effects of fatness on reproductive success may in some circumstances be compounded in humans across generations. Daughters of fatter mothers, as a group, reach menarche earlier than the thinner daughters of thinner mothers (Garn et al. 1983), they remain fatter throughout life and give birth to larger babies at each age (because of age-specific effects of fatness; Beazley and Swinhoe 1979), and evidence from a number of societies indicates that age at first birth correlates with age at menarche (Udry and Cliquet 1982).

Thus, maternal fatness does have positive effects on growth, survival, and reproduction of offspring and grandoffspring. Given that a) breast size is significantly positively correlated with body weight, percent fat in the body and most fatfold and girth measurements (Katch et al. 1980); b) women sequester absolutely more fat in the iliac region when they gain weight (Garn et al. 1987) and tend to retain fat there when they lose it (Garn and Brozek 1956); and c) fat cells in the iliac region are of a specialized type that only mobilize their stores during lactation (Rebuffe-Scrive et al. 1985), it seems most probable that fat in these regions of the body does correlate with future reproductive success. Whether it also functions as a signal of this to males is, at present, equivocal. 
It is important to note that many of the studies cited above do reveal an inverted U-shaped curve of fitness measures with fatness. At low-tointermediate levels of fatness, fat is advantageous for reproduction both with respect to becoming pregnant and the ability to carry the fetus to term. At the higher levels of fatness, however, menstrual cycles are less frequent and irregular, and the conceptus tends to be of disadvantageously high birth weight with respect to survival. Moreover, the points of inflection for conception and various components of reproduction occur at different levels of fatness. However, we do not expect that the extreme levels of fatness attained by some women in modern Western societies were reached by individuals during the prehistoric period of human evolution.

\section{CONCLUSION}

If there are no effects of breast fat or hip fat on women's fecundity (e.g., factors such as earlier menarche, interbirth interval, or probability of successfully giving birth) and on all other measures of reproductive success, such as prenatal investment (e.g., offspring birthweight relative to mothers's weight), postnatal investment (e.g., milk production and length of offspring dependence), and longevity (e.g., mother's ability to survive food shortages), the Deceptive Hypothesis requires serious consideration (Caro 1987). However, the available evidence strongly suggests that there are positive effects of hip and breast fat on individual fitness. Therefore, it is most parsimonious to assume that all differences in pattern of fat distribution in individual women are either an honest signal of differences in some aspect of their reproductive performance, as many have argued (e.g., Cant 1981; Gallup 1982; Huss-Ashmore 1980) or simply reflect individual differences in patterns of fat storage with no signal function at all (Masia-Lees et al. 1986).

We thank Monique Borgerhoff Mulder, Janet Mann, and Alisa Harrigan for advice; and Stanley Garn, Joseph Manson, Virginia Vitzthum, referees, and particularly Monique Borgerhoff Mulder and Daniela Sieff for comments. After this manuscript was submitted, Judith Anderson's (1988) article appeared in this journal; it agrees with several of the arguments presented here as well as providing useful additional ones. We hope it will be read in conjunction with this paper.

\section{REFERENCES}

Alexander, R.D. The search for an evolutionary philosophy of man. Proceedings of the Royal Society Victoria 84: 99-120. 1971.

- , and Noonan, K.M. Concealment of ovulation, parental care and human social evolution. In: Evolutionary Biology and Human Social Behaviour: An Anthropological Perspective, N.A. Chagnon and W. Irons (Eds.). North Scituate, MA: Duxbury Press, 1979, pp. $436-453$. 
Anderson, J.L. Breasts, hips, and buttocks revisited: Honest fatness for honest fitness. Ethology and Sociobiology 9: 319-324, 1988.

Beazley, J.M., and Swinhoe. J.R. Body weight in parous women: Is there any alteration between successive pregnancies? Acta Obstetrics and Gynecology of Scandinavia 58: 45-47, 1979.

Bongaarts, J. Does malnutrition affect fecundity? A summary of the evidence. Science 208: 564-569, 1980.

Borell, U., and Fernstrom, I. The movements at the sacro-iliac joints and their importance to changes in the pelvic dimensions during parturition. Acta Obstetrica et Gynecologia Scandinavia 36: 42-57, 1957.

Borgerhoff Mulder, M. Resources and reproductive success in women with an example from the Kipsigis of Kenya. Journal of Zoology 213: 489-505, 1987.

- Kipsigis bridewealth payments. In: Human Reproductive Behaviour: A Darwinian Perspective, L.L. Betzig, M. Borgerhoff Mulder, and P.W. Turke (Eds.). Cambridge: Cambridge University Press, 1988, pp. 65-82.

Boston Women's Health Book Collection, The New Our Bodies Our Selves, New York: Simon and Schuster Inc, 1984, p. 480.

Bowen-Jones, A., Thompson C., and Drewett, R.F. Milk flow and suckling rates during breastfeeding. Developments in Medical Child Neurology 24: 626-633, 1982.

Broude, G.E. and Greene, S.J. Crosscultural codes on twenty sexual attitudes and practices. Ethnology 15: 410-429, 1976.

Buss, D.M. Sex differences in human mate preferences: Evolutionary hypotheses tested in 37 cultures. Behavioral Brain Sciences 12: 1-49, 1989.

Cant, J.G.H. Hypothesis for the evolution of human breasts and buttocks. American Naturalist 117: 199-204, 1981.

Caro, T.M. Human breasts: Unsupported hypotheses reviewed. Human Evolution 2: 271-282, 1987.

Chen, L.C., Chowdhury, M.A., and Huffman, S.L. Anthropometric assessment of energyprotein malnutrition and subsequent risk of mortality among preschool-aged children. American Journal of Clinical Nutrition 33: 1836-1845, 1980.

Delgado, M.L., Martorell, R., and Klein, R.E. Nutrition, lactation and birth interval components in rural Guatemala. American Journal of Clinical Nutrition, 35: 1468-1476, 1982.

Ember, C. The relative decline in women's contribution to agriculture with intensification. American Anthropologist 855: 285-304, 1983.

Estioko-Griffin, A., and Griffin, P.B. Woman the hunter: The Agta. In Woman The Gatherer, F. Dahlberg (Ed.). New Haven: Yale University Press, 1981, pp. 121-151.

Frayser, S.G. Chapter 4. In Varieties of Sexual Experience. New Haven, CT: Human Relations Area Files, 1985, pp. 314-321.

Frisancho, A.R., Klayman, J.E., and Matos, J. Newborn body composition and its relationship to linear growth. American Journal of Clinical Nutrition 30: 704-711, 1971.

,-- , and - Influence of maternal nutritional status on prenatal growth in a Peruvian urban population. American Journal of Physical Anthropology 46: 265-271, 1977.

Gallup, G.G. Permanent breast enlargement in human females: A sociobiological analysis. Journal of Human Evolution 11: 597-601, 1982.

Garn, S.M. Optimal nutritional assessment. In Nutrition and Growth Vol. 2, S.B. Teliffe and E.F.P. Teliffe (Eds.) New York: Plenum Press, 1979, pp. 273-298.

-. Relationship between birth weight and subsequent weight gain. American Journal of Clinical Nutrition 42: 57-60, 1985.

- and Brozek, J. Fat changes during weight loss. Science 124: 682, 1956.

- , and Keating, M.T. Effect of various prenatal determinants on size and growth through seven years. Ecology of Food and Nutrition 9: 109-112, 1980.

-, and LaVelle, M. Two-decade follow-up of fatness in early childhood. American Journal of Diseases of Children 139: 181-185, 1985a.

reproduction and mortality. In The Underweight Infant, Child, and Adolescent, S.A. Cohen (Ed.). Norwalk, CT: Appleton-Century-Crofts, 1985b, pp. 303-317.

,-- , and Pilkington, J.J. Comparisons of fatness in premenarcheal and postmenarcheal girls of the same age. Journal of Pediatrics 103: 328-331, 1983. 
- - and Pesick, S.D. Relationship between various maternal body mass measures and size of the newborn. American Journal of Clinical Nutrition 36: 664-668, 1982.

and Nutrition 12: 65-67, 1982.

and - Characteristics of mother and child in teenage pregnancy. American Journal of Child Disorders 137: 365-368, 1983.

- Rosenberg, K.R., and Schaefer, A.E. Relationship between fatness level and size attainment in central America. Ecology of Food and Nutrition 13: 157-165, 1983.

- Shaw, H.A., and McCabe, K.D. Effects of socioeconomic status and race on weightdefined and gestational prematurity in the United States. In The Epidemiology of Prematurity, D.W. Reed and F.J. Stanley (Eds.). Baltimore: Urban \& Schwarzenberg, 1977, pp. 127-143.

- - - - and McCabe, K.D. Effect of socioeconomic status on early growth as measured by three different indicators. Ecology of Food and Nutrition 77: 51-55, 1978.

- Sullivan, V., and Hawthorne, M. Differential rates of fat change relative to weight change at different body sites. International Journal of Obesity 11: 519-525, 1987.

Graham, S.B. Running and menstrual dysfunction: recent medical discoveries provide new insights into the human division of labor by sex. American Anthropologist 87: 878$882,1985$.

Gray, J.P., and Wolfe, L.D. Parental certainty, subsistence and inheritance revisited. Journal of Human Evolution 10: 277-280, 1981

Greene, D.L., and Sibley, L. Neandertal pubic morphology and gestation length revisited. Current Anthropology 27: 517-518, 1986.

Hames, R.B. The allocation of parental care among the Ye'kwana. In Human Reproductive Behaviour: A Darwinian Perspective, L.L. Betzig, M. Borgerhoff Mulder, and P.W. Turke (Fds.). Cambridge: Cambridge University Press, pp. 237-252, 1988.

Hill, K., and Kaplan, H. Tradeoffs in male and female reproductive strategies among the Ache: Part 2. In Human Reproductive Behaviour: A Darwinian Perspective. L.L. Betzig. M. Borgerhoff Mulder, and P.W. Turke (Eds.). Cambridge University Press: Cambridge, 1988, pp. 291-306.

Huss-Ashmore, R. Fat and fertility: Demographic implications of differential fat storage. Yearbook of Physical Anthropology 23: 65-91. 1980.

Hurtado, A.M., Hawkes, K., Hill, K., and Kaplan, H. Female subsistence strategies among Ache hunter-gatherers of Eastern Paraguay. Human Ecology 13: 1-28, 1985.

Hytten, F.E. Clinical and chemical studies in human lactation. VI. The functional capacity of the breast. British Medical Journal 1: 912-915, 1954.

- , and Leitch, 1. The Physiology of Human Pregnancy, 2nd Ed., Oxford: Blackwell, 1971.

Johnston, M., and Everitt, B. Essential Reproduction, 2nd ed., Oxford: Blackwell, 1984.

Kaplan, H., and Hill, K. Food sharing among Ache foragers: Test of explanatory hypotheses. Current Anthropology 26: 233-245, 1985.

Katch, V.L., Campaigne, B., Freedson, P., Sady, S., Katch, F.I., and Behnke, A.R. Contribution of breast volume and weight to body fat distribution in females. American Journal of Physical Anthropology 53: 93-100, 1980.

Keen. H.. Thomas, B.J., and Jarret1, R.J. Obesity and cardiovascular risk. International Journal of Obesity 6:(Suppl. 1): 83-89, 1982.

Kennedy, J.L., and Greenwald, E. Correlation of shoe size and obstetric outcome: an anthropometric study. American Journal of Obstetrics and Gynecology 140; 466-467. 1981.

Keys. A., Fidanza, F., Karvonen, M.J., Kimura, N., and Taylor, H.L. Indices of relative weight and obesity. Journal of Chronic Diseases 25: 329-343, 1972.

Krebs, J.K., and Davies, N.B. An Introduction to Behavioural Ecology, 2nd Ed.. Oxford: Blackwell, 1987.

Kriewall, T.J., and McPherson, G.K. Effects of uterine contractility on the fetal cranium: Perspectives from the past, present and future. In Advances in Prenatal Medicine, Volume 1. A. Milunsky, E.A. Friedman, and L. Gluck (Eds.). New York: Plenum Press, 1981, pp. 295-353.

Larsson. B.. Svardsudd, K., Welin. L.. Wilhelmsen, L., Bjorntorp, P., and Tibblin, $G$. Abdominal adipose tissue distribution, obesity and the risk of cardiovascular dis- 
ease and death: 13 year follow up of participants in the study of men born in 1913 . British Medical Journal 288: 1401-1404, 1984.

LaVelle Moerman, M. A Longitudinal Study of Growth in Relation to Body Size and Sexual Dimorphism in the Human Pelvis, PhD, University of Michigan, 1981.

- Growth of the birth canal in adolescent girls. American Journal of Obstetrics and Gynecology 143: 528-532, 1982.

Lee, R.B. What hunters do for a living: Or how to make out on scarce resources. In Man the Hunter, R.B. Lee and I. DeVore (Eds.). Chicago: Aldine, 1968, pp. 30-48.

Llewellyn-Jones, D. Fundamentals of Obstetrics and Gynecology, 3rd ed., London: Faber and Faber, 1982.

Loudon, A.S.I., McNeilly, A.S., and Milne, J.A. Nutrition and lactational control of fertility in red deer. Nature 302: 145-147, 1983.

Low, B.S. Sexual selection and human ornamentation. In Evolutionary Biology and Human Social Behavior: An Anthropological Perspective, N.A. Chagnon and W. Irons (Eds.). North Scituate, MA: Duxbury, 1979, pp. 462-487.

- Alexander, R.D., and Noonan, K.M. Human hips, breasts and buttocks: Is fat deceptive? Ethology and Sociobiology 8: 249-257, 1987.

,,-- and - Response to Judith Anderson's comments on Low, Alexander and Noonan (1987). Ethology and Sociobiology 9: 325:328, 1988.

Malina, R.M. Menarche in athletes: A synthesis and hypothesis. Annals of Human Biology 10: $1-24,1983$.

Masia-Lees, F.E., Relethford, J.H., and Sorger, T. Evolutionary perspectives on permanent breast enlargement in human females. American Anthropologist 88: 423-429, 1986.

McNeilly, A.S. Physiology of lactation. Journal of Biosocial Science 4(Suppl.): 5-21, 1977.

Naeye, R.L. Teenaged and pre-teenaged pregnancies: Consequences of the fetal-maternal competition for nutrients. Pediatrics 67: 146-150, 1981.

Nabarro, D. Social, economic, health and environmental determinants of nutritional status. United Nations University Food and Nutrition Bulletin 6: 18-32, 1984.

Oxorn, H. Human Labor und Birth, 5th Ed., Norwalk, CT: Appleton-Century-Crofts, 1986.

Prentice, A.M., Cole, T.J., Foord, F.A., Lamb, W.H., and Whitehead, R.G. Increased birthweight following prenatal dietary supplementation of rural African women. American Journal of Clinical Nutrition, 46: 912-925, 1987.

—_, Paul, A.A., Prentice, A., Black, A.E., Cole, T.J., and Whitehead, R.G. Cross-cultural differences in lactational performance. In Human Lactation-Maternal and Environmental Factors, M. Hamosh and A.S. Goldman (Eds.). New York: Plenum, 1986 (October 1985), pp. 13-44.

—, Roberts, S.B., Prentice, A., Paul, A.A., Watkinson, M., Watkinson, A.A., and Whitehead, R.G. Dietary supplementation of lactating Crambian women. I. Effect of breast milk volume and quality. Human Nutrition: Clinical Nutrition 37C: 65-74, 1983.

- and Whitehead, R.G. The energetics of human reproduction. Symposia of the Zoological Society of London 57: 275-304, 1987.

Rebuffe-Scrive, M., Enk, L., Crona, N., Lonnroth, P., Abrahansson, L., Smith, U., and Bjorntorp, P. Fat cell metabolism in different regions in women. Effect of menstrual cycle, pregnancy, and lactation. Journal of Clinical Investigation 75: 1973-1976, 1985.

Rosenburg, K.R. The functional significance of Neandertal pubic length. Current Anthropology 29: 595-617, 1988.

Russell, J.G.B. Radiology and Obstretrical and Antenatal Paediatrics, Will Clowes and Sons: London, 1973.

- - and Richards, B. A review of pelimetry data. British Journal of Radiology 44: 780-784, 1971.

Saether, B.E. Life history of the moose Alces alces: relationship between growth and reproduction. Holarctic Ecology 8: 100-106, 1985.

Seidell, J.C., Bakx, J.C., Boer, E.D., Deurenberg. P., and Hautvast, J.G.A.J. Fat distribution of overweight persons in relation to morbidity and subjective health. International Journal of Obesity 9: 363-374. 1985.

Sjostrom, L., Smith, U., Krotkiewski, M., and Bjorntrop, P. Cellularity in different regions of adipose tissue in young men and women. Metabolism 21: 1143-1149. 1972.

Stewart, D.B. The pelvis as a passageway. I. Evolution and adaptations. British Journal of Obstetrics and Gynaecology 91: 611-617, 1984. 
66 T. M. Caro and D. W. Sellen

Strassmann, B.I. Sexual selection, parental care and concealed ovulation in humans. Ethology and Sociobiology 2: 31-40, 1981.

Trevathan, W.R. Human Birth: An Evolutionary Perspective, New York, 1987.

Comment on Rosenburg's "The functional significance of Neandertal pubic length." Current Anthropology 29: $611,1988$.

Trivers, R. Social Evolution, Menlo Park: Benjamin/Cummings, 1985.

Udry, J.R., and Cliquet, R.L. Cross-cultural examination of relationships between ages at menarche, marriage and firth birth. Demography 19: 53-63, 1982.

Wiggins, J.S., Wiggins, N., and Conger, J.C. Correlates of heterosexual somatic preference. Journal of Personality and Social Psychology 10: 82-90, 1968. 